\title{
Review
}

\section{Serial killers: ordering caspase activation events in apoptosis}

\author{
EA Slee ${ }^{1}$, C Adrain ${ }^{1}$ and SJ Martin ${ }^{\star, 1}$ \\ ${ }^{1}$ Division of Molecular \& Cell Biology, Smurfit Institute of Genetics, Trinity \\ College, Dublin 2, Ireland \\ * Corresponding author: SJ Martin, Division of Molecular \& Cell Biology, \\ Smurfit Institute of Genetics, Lincoln Place Gate, Trinity College, Dublin 2, \\ Ireland. Tel: +353-1-608 1289; Fax: +353-1-679 8558; \\ E-mail: martinsj@tcd.ie
}

Received 28.5.99; revised 23.8.99; accepted 21.9.99

Edited by D Nicholson

\begin{abstract}
Caspases participate in the molecular control of apoptosis in several guises; as triggers of the death machinery, as regulatory elements within it, and ultimately as a subset of the effector elements of the machinery itself. The mammalian caspase family is steadily growing and currently contains 14 members. At present, it is unclear whether all of these proteases participate in apoptosis. Thus, current research in this area is focused upon establishing the repertoire and order of caspase activation events that occur during the signalling and demolition phases of cell death. Evidence is accumulating to suggest that proximal caspase activation events are typically initiated by molecules that promote caspase aggregation. As expected, distal caspase activation events are likely to be controlled by caspases activated earlier in the cascade. However, recent data has cast doubt upon the functional demarcation of caspases into signalling (upstream) and effector (downstream) roles based upon their prodomain lengths. In particular, caspase-3 may perform an important role in propagating the caspase cascade, in addition to its role as an effector caspase within the death programme. Here, we discuss the apoptosis-associated caspase cascade and the hierarchy of caspase activation events within it.
\end{abstract}

Keywords: apoptosis; apoptosome; cascade; caspase; protease

Abbreviations: AIF, apoptosis-inducing factor; Apaf-1, apoptotic protease activating factor; CAD, caspase-activated deoxyribonuclease; CARD, caspase recruitment domain; DR, death receptor; DFF45; DNA fragmentation factor-45; FADD, Fas-associated protein with a death domain; IAP, inhibitor of apoptosis protein; ICE, interleukin- $1 \beta$ converting enzyme; IL-1 $\beta$, interleukin-1 $\beta$; NK, natural killer; PARP, poly (ADP-ribose) polymerase; RAIDD, RIP and Ich-1 homologous protein with a death domain; TNF, tumour necrosis factor; TRADD, TNF receptor associated protein with a death domain; TRAIL, TNF-related apoptosis-inducing ligand

\section{Introduction}

The hydrolysis of a peptide bond is a simple yet powerful means of altering the activity of a protein. It is hardly surprising then that proteases - enzymes that catalyse the cleavage of peptide bonds - are used to modify protein activities in numerous biological contexts. At their most primitive, proteases serve to degrade proteins at multiple sites during protein digestion and metabolism. However, with the acquisition of greater specificity, proteases can be harnessed to perform more subtle alterations to proteins that modify rather than destroy activity. ${ }^{1}$

Proteases participate in protein destruction and the regulation of protein activities in numerous cellular contexts. Proteases act as protein blenders outside of the cell (digestive proteases), and in a similar but more discriminating manner within the cell (proteasomes). They participate in protein maturation (e.g. caspase-1 in the context of pro-IL-1 $\beta$ maturation), and export (e.g. the trypsin-like proteases of the Spätzle/Toll ligand pathway). Proteases also act as regulatory molecules that amplify and feed forward reactions that culminate in explosive endpoints (e.g. the clotting and complement cascades) and finally, as demolition experts that allow cells to migrate (proteases of the extracellular matrix) or die (proteases of the cell death machinery).

In the context of cell death, proteases participate in several guises; as triggers of the death programme, as regulatory elements within it, and ultimately as a subset of the effector elements of the machinery itself. Numerous reviews have detailed how genetic screens for proteins that regulate programmed cell death in $C$. elegans yielded CED3 - a cysteine protease with an unusual substrate specificity for Asp residues - which soon led to the discovery of its mammalian relatives (the caspases). ${ }^{2}$ Since then, a large number of CED-3-related proteases have been cloned - 14 in mammals - but it is unlikely that they all participate in apoptosis. This embarrassment of riches has revealed that the cell death machinery is wonderfully complex, but we still have a good way to go before we understand how all of the components interact. In this review, we will restrict ourselves to a discussion of the role that caspases play in the death machinery and in particular we will summarize what is known concerning the hierarchical activation of caspases within the context of different pro-apoptotic stimuli.

\section{Regulation of proteolysis}

Although it is clear that proteases play very constructive roles both inside as well as outside of the cell, their destructive tendencies need to be carefully controlled to minimize the 
threat of damage to proteins other than their intended targets. For this reason, the potentially destructive forces of proteases are typically muzzled within the cell until their services are required. This is usually achieved in two basic ways: (1) many proteases are synthesized as inactive pro-enzymes (zymogens) that require removal of a pro-peptide by limited proteolysis, and (2) cells typically synthesise proteins that can complex with proteases and inhibit their activities (protease inhibitors). Both strategies are utilized in the control of cell death-related proteases.

For example, it is well established that the majority of the caspases are constitutively expressed as inactive pro-forms that require limited proteolysis to become active. Because the proteolytic cleavage events that convert caspase proforms to their active forms occur at Asp residues within the caspase, this suggests that caspases must either cleave themselves or become activated by other caspases. It is this important fact which establishes the potential for a caspase cascade, but it also poses the question of how the cascade can be instigated. As we shall see, proteins that promote aggregation of caspases play a particularly important role in proximal caspase activation events.

Protease inhibitors are also heavily exploited within the cell death machinery to regulate protease activities. The IAP family (X-IAP, c-IAP-1, c-IAP-2, N-AIP) appear to negatively regulate caspase activities by acting as pseudosubstrates for the caspases, binding to active caspases and neutralizing their activity. ${ }^{3,4} \mathrm{~A}$ different strategy is utilized by another class of inhibitor - the pseudocaspases - which have evolved by gene duplication events but have lost enzymatic activity. These pseudocaspases can integrate into caspase activation complexes (e.g. c-FLIP competes with caspase-8 for binding to FADD at the cytoplasmic face of the CD95/Fas/APO-1 receptor) and attenuate caspase activation as a consequence. ${ }^{5}$

\section{The caspases}

To date, 14 caspases have been identified in mammals. ${ }^{6}$ Of these, eleven have been cloned in humans, with caspases$11,-12$ and -14 only conclusively identified in the mouse thus far. ${ }^{7,8}$ Multiple caspases are also present in other organisms; four have been identified in Drosophila melanogaster, ${ }^{9-13}$ at least two active caspases have been found in Caenorhabditis elegans, ${ }^{2,14}$ two have been found in Xenopus laevis, ${ }^{15}$ and one in the insect Spodoptera frugiperda. ${ }^{16}$ The presence of more than one caspase in organisms like $C$. elegans, and the fact that they are able to process each other, ${ }^{14}$ suggests that caspase cascades are unlikely to be confined to mammalian cells.

Functionally, the mammalian caspases can be divided into two broad families; those that are thought to be centrally involved in cell death (caspases -2, -3, -6, -7, -8, -9 , and -10 ) and those most closely-related to caspase-1 (also called ICE) whose primary role seems to be in cytokine processing (caspases -1, -4, -5 and -11). At present, there is insufficient data available to enable caspases $-12,-3$ and -14 to be categorized, although in terms of their primary structure, caspases -12 and -13 appear to be related to the cytokine processing sub- family, ${ }^{8,17}$ whereas caspase-14 is more related to the cell death family caspases -2 and $-9 .{ }^{18}$ Comparatively little is known about the caspases that are involved in cytokine processing and the manner in which they are activated beyond the fact that caspase-11-deficient mice are unable to activate caspase- 1 and that caspase- 1 may be activated by oligomerization. ${ }^{19,20}$ However, our knowledge of the manner in which activation of the cell death-related caspases is achieved is more advanced and will form the basis for much of the subsequent discussion.

\section{The phases of death: initiation, commitment, amplification and demolition}

For convenience, we have divided the death programme into separate phases (Figure 1). The 'initiation' phase, during which cells receive signals that may result in the activation of the death programme. The 'commitment' phase, the point after which death signals become irreversible. The 'amplification' phase, where multiple caspases are recruited to cooperate in the destruction of the cell, and finally, the 'demolition' phase, where a panoply of active caspases dismantle cellular structures, either directly, or via activation of other enzymes (such as CAD/DFF45). We will consider each of these phases in turn.

\section{Initiation: activation of apical caspases}

Initiators of the apoptosis machinery can be broadly grouped into three different categories: (1) death receptors, (2) the contents of cytotoxic T and NK cell granules, and (3) stimuli that provoke generalized cellular damage.

\section{Death receptor-initiated cell death signals}

The death receptors (CD95/Fas/APO-1, TNFR1, DR3/WSL-1/ TRAMP, DR4/TRAIL-R1, DR5/TRAIL-R2, DR6) are a subset of the TNF/NGF receptor family of cell surface molecules that possess a common motif within their cytoplasmic tails, called the death domain. ${ }^{21,22}$ The death domains of these receptors are responsible for recruiting adaptor molecules that, in turn, recruit caspases to the receptor complex. This simple strategy greatly increases the probability of caspase activation by facilitating cross processing of caspases within the cluster. This proximity-induced processing is thought to drive apical caspase activation events that are initiated by all of the death receptors. ${ }^{23,24}$ Thus, death receptors can drive caspase activation in a very direct manner. The best characterized receptors in this regard are the CD95 and TNFR1 receptors that use the FADD and TRADD adaptors to recruit caspase$8 .^{21}$ It has also been suggested that TNFR1 recruits caspase2 via the RAIDD/CRADD adaptor molecule, ${ }^{25}$ however the biological significance of this is unclear since TNF and CD95L-induced apoptosis are completely absent in cells derived from CASP-8 null mice. ${ }^{26}$ Moreover, CASP-2 null mice do not display defects in the CD95/Fas or TNFR1initiated cell death pathways. ${ }^{27}$ The adaptors and the caspases that are recruited into the DR4/TRAIL-R1, DR5/ TRAIL-R2, and DR6 signalling complexes are currently unknown. 
So what happens upon activation of caspase-8 in the context of CD95 or TNFR1 receptor signalling? A simple and appealing model is that caspase- 8 then propagates the death signal by direct processing of other caspases. Caspase-3 in particular appears to be a very good substrate for caspase- $8 .{ }^{28}$ This has been endorsed using

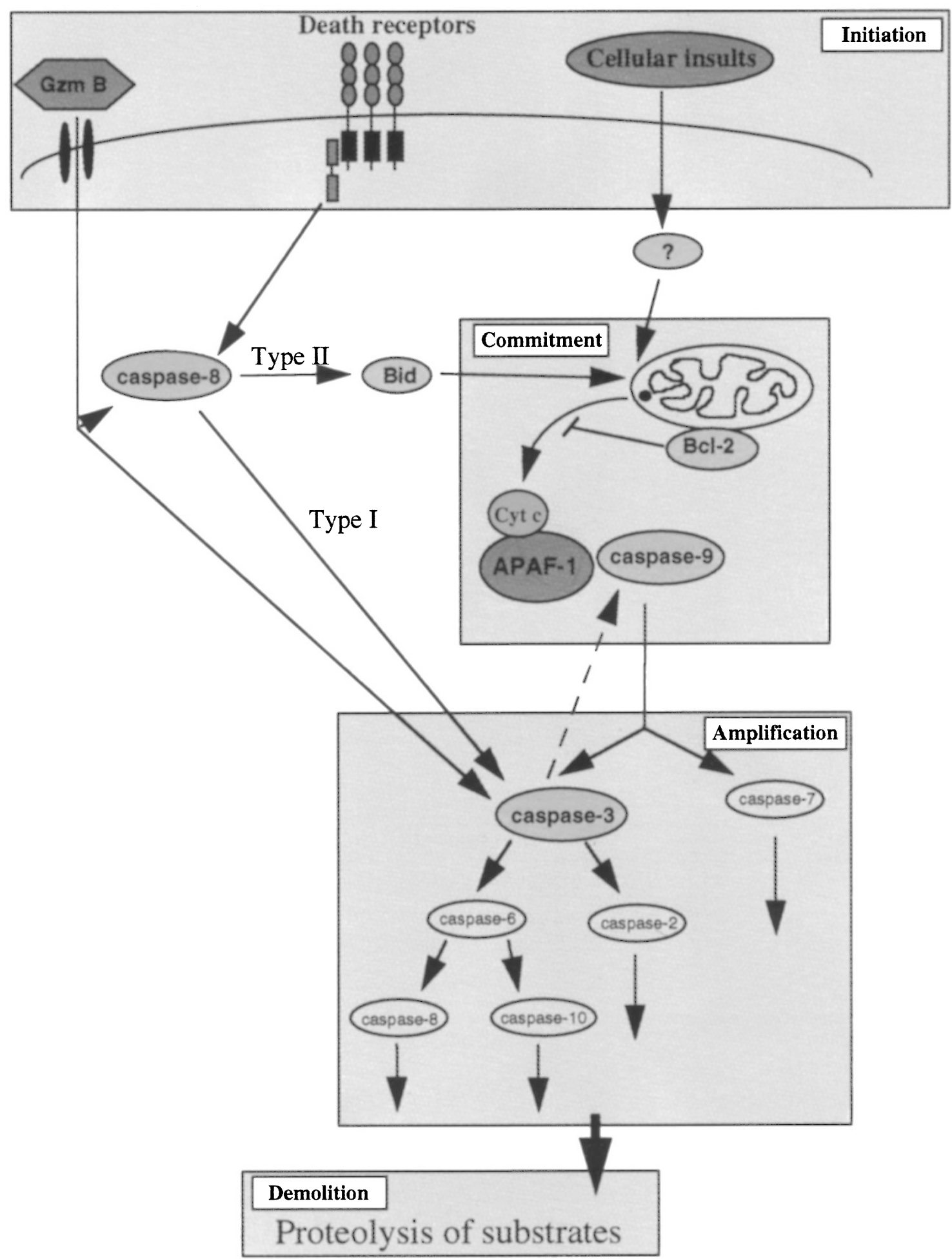

Figure 1 Schematic representation of the routes to caspase activation within the cell death programme. See main text for details of each of the four phases (initiation, commitment, amplification and demolition) 
peptide inhibitors and affinity labelling techniques which indicate that caspase -3 and -7 are simultaneously activated by caspase- $8 .{ }^{29}$ Once activated, caspase- 3 can then propagate the cascade further by activation of other caspases such as caspase-6 and caspase-2 (Figure 1). ${ }^{29,30}$ This model seems to fit the majority of CD95L and TNF-initiated cell deaths and in this context death repressor proteins such as $\mathrm{Bcl}-2$ are unable to intervene. However, a subset of CD95L and TNF-initiated cell deaths do not fit this model since $\mathrm{Bcl}-2$ and $\mathrm{Bcl}-\mathrm{x}$ do protect from FasL or TNF in certain cell types. ${ }^{31}$ Because several members of the Bcl-2 family, including Bcl-2 itself, appear to exert their effects on the cell death pathway by regulating mitochondrial events, this implicates the mitochondrial pathway in a subset of receptor-initiated cell deaths. This had led to the proposal that two distinct routes to apoptosis initiated by the TNF and CD95 death receptors exist. ${ }^{31}$ In type I cells, the direct pathway is engaged and Bcl-2 fails to protect in this context. In type II cells, Bcl-2 and Bcl-x can confer protection because the death signal is routed through the mitochondria.

So how does caspase-8 engage the mitochondrial pathway? Recent data suggests that BID, a death promoting member of the $\mathrm{Bcl}-2$ family, is the intermediary in this context. ${ }^{32-34}$ Unlike most other members of the Bcl2 family, BID is normally localized to the cytoplasm. However, caspase-8 can catalyze the cleavage of BID, the C-terminal portion of which then translocates to the mitochondria where it integrates into the outer membrane and provokes the release of cytochrome c - an important accessory molecule for downstream caspase activation events. How BID triggers cytochrome $c$ release is currently unknown, but it is well established that $\mathrm{Bcl}-2$ and $\mathrm{Bcl}-\mathrm{x}$ can regulate this event, ${ }^{35,36}$ thereby explaining how TNF and CD95L-induced death signals can be regulated in type II cells.

\section{Cytotoxic lymphocyte-initiated death signals}

Cytotoxic lymphocytes (T and NK cells) contain granules that can be discharged onto the surface of target cells, delivering what has been called 'the kiss of death' (Figure 1). These granules contain, amongst other things, granzyme B (also called fragmentin-2) a serine protease which cleaves after Asp residues, and a pore-forming protein called perforin (or cytolysin) that is likely to permit entry of the other granule components into the target cell. This immediately suggests a mechanism for cytotoxic lymphocyte-initiated apoptosis where granzyme $B$ enters the cell and triggers the caspase cascade by directly cleaving and activating caspases. ${ }^{37,38}$ While it has been demonstrated that granzyme B can cleave most of the caspases in vitro, it appears that in cells its preferred target is caspase- 3 , which then proceeds to activate caspases $-7,-8$ and $-9 .{ }^{39}$

\section{Generalized cellular damage-initiated death signals}

All other stimuli that can provoke apoptosis have been grouped into this category, mainly because it is still far from clear how these stimuli engage the caspase component of the death machinery. This group includes diverse apoptosispromoting stimuli such as cytotoxic drugs, radiation, heat shock, survival factor deprivation and other cellular stresses. The signals that these stimuli evoke within the cell are disparate, but the death pathways engaged by the vast bulk of these stresses seem to converge on the mitochondria. ${ }^{35}$ Furthermore, Bcl-2 and $\mathrm{Bcl}-\mathrm{x}$ protect in the majority of these cases, again implicating the mitochondrial pathway as an important conduit for death signals triggered by stimuli within this group. ${ }^{35}$ Thus, although cytotoxic drugs, radiation and heat shock may injure cells in very different ways, all of these pathways appear to engage the mitochondrial apoptosome by triggering the release of certain mitochondrial components (Figure 1).

\section{Commitment: mitochondrial damage?}

Recently, considerable effort has focused upon the role of the mitochondrion in transducing pro-apoptotic stimuli. ${ }^{40-44}$ A discussion of all of the evidence that has implicated the mitochondrion as an important sensor of cellular damage is outside of the scope of the present review. However, to summarize, it appears that numerous pro-apoptotic stimuli provoke changes in the permeability of the mitochondrial outer membrane that permits escape of certain proteins such as AIF and cytochrome c - that are normally confined to the mitochondrial intermembrane space. How these proteins escape is the subject of much debate, but it is clear that this can be achieved in a caspasedependent (via caspase-8 cleavage of BID) or caspaseindependent (unknown effectors) manner, depending on the nature of the pro-apoptotic stimulus. Thus, the death receptor and cytotoxic T/NK cell granule-initiated pathways can provoke the caspase-dependent route to mitochondrial damage (via caspase-8) whereas the majority of other death-promoting stimuli seem to achieve this via as yet unidentified factors (Figure 1). Irrespective of the way in which mitochondrial damage is achieved, the consequences of cytochrome $\mathrm{c}$ and AIF leakage are likely to be the same in both contexts.

AIF appears to exert its effects in a caspaseindependent manner by translocating to the nucleus and triggering the chromatin collapse and digestion into high molecular weight fragments that is commonly observed during apoptosis. ${ }^{41}$ In contrast, cytochrome $\mathrm{c}$ exerts its effects by regulating the activities of Apaf-1, a molecule that can promote clustering of caspase-9. ${ }^{40,45-49}$ Cytochrome $c$ achieves this by binding to Apaf-1 - probably in the WD-40 repeat region of the molecule - which, in association with ATP, facilitates the assembly of a high molecular weight complex (the mitochondrial apoptosome) composed of several Apaf-1 molecules, each of which has bound a molecule of caspase- 9 via its $\mathrm{N}$-terminal CARD domain (Figure 2). This process bears a lot of similarity to the aggregation of caspases that is achieved by the cell surface death receptors. Thus, Apaf-1 promotes caspase- 9 activation via a proximity-induced processing strategy which drives the next phase of the caspase cascade. 


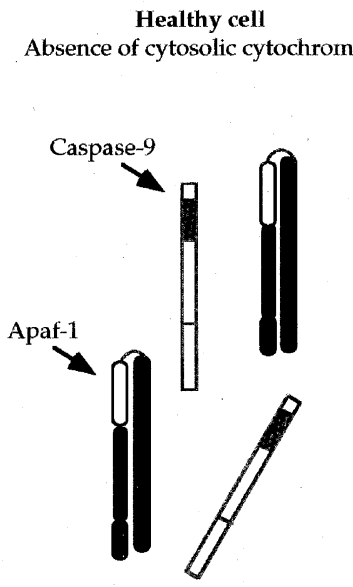

Caspase- 9 binding and Apaf- 1 dimerization is repressed by the WD-40 repeat region

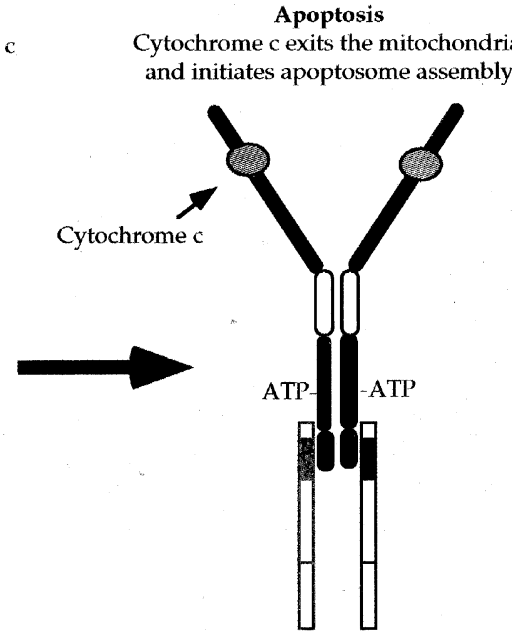

In the presence of cytochrome $\mathrm{c}$ and ATP caspase- 9 is recruited to the CED-3 homology region and dimerization of Apaf- 1 occurs via the CED-4/linker domains

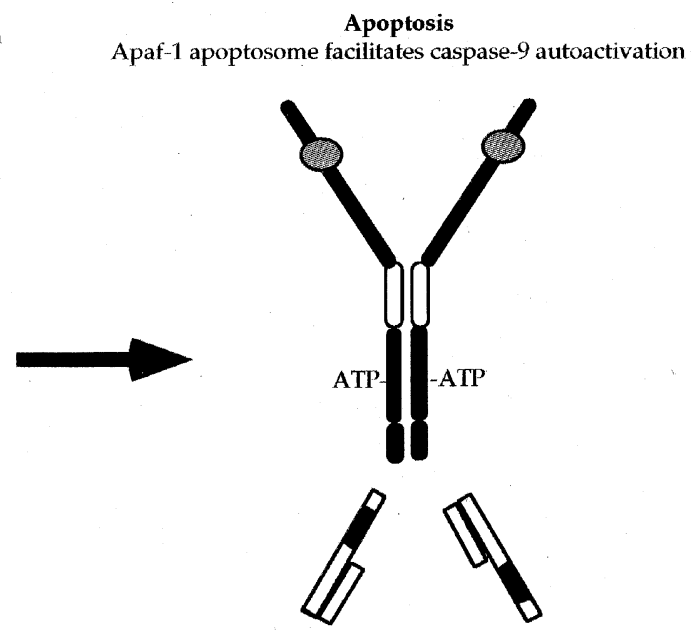

Proximity-induced processing of adjacent caspase- 9 molecules results in their activation

Figure 2 Apaf-1 promotes caspase-9 activation by oligomerization. Cytochrome $c$ and ATP regulate the ability of Apaf- 1 to recruit caspase-9 and form multimers

\section{Amplification: activation of 'downstream' caspases}

Upon activation of caspase-9 by Apaf-1, this caspase can then propagate the death signal by activating other caspases. The study of this phase of the death programme has been greatly facilitated by the observation that cytochrome c (in conjunction with dATP) can trigger apoptosis in cell-free extracts, an unusual property that is not displayed by the vast majority of agents that can promote apoptosis in intact cells. ${ }^{30,40,46}$ Studies using cell-free systems have revealed that cytochrome $c$ activates caspase-9 (via Apaf-1) and that caspase- 9 then initiates a series of other caspase activation events that represent a bona fide caspase cascade, since removal of certain members of the cascade blocks subsequent events (see Figure 1). ${ }^{30}$

The caspase activation events driven by caspase- 9 appear to be the simultaneous activation of caspases -3 and $-7 .^{30,47,50}$ Caspase- 3 then drives the activation of caspases -2 and -6 , followed by the activation of caspases -8 and $-10 . .^{30}$ In the absence of caspase-3, caspases -7 and -9 are still activated but activation of other caspases downstream of this point (see Figure 1) is arrested. ${ }^{30}$ Removal of caspase- 6 blocked the activation of caspases -8 and -10 in this context, suggesting that these activation events are, somewhat surprisingly, driven by caspase- $6 .^{30}$ The activation of long-prodomain caspases late in this cascade may be unexpected, but these observations are bolstered by similar observations in other systems. In addition, it seems quite plausible that caspases that are apical (initiator) caspases in the context of certain proapoptotic stimuli may participate in an amplification role in other contexts. This phase of the death programme may serve as an amplification step that activates the full complement of caspases that are required to dismantle the cell in the appropriate manner.

It is important to note that not all of the caspases that are activated during this phase may be necessary for the cell to die per se. However, they are likely to be required for the cell to adopt the typical apoptotic phenotype. For example, cells deficient in caspase-3 (either from CASP-3 null mice, or due to a frameshift mutation, i.e. MCF-7 cells) clearly die in response to many pro-apoptotic stimuli. ${ }^{51-53}$ However, caspase-3-deficient cells undergo an aberrant form of apoptosis (restricted blebbing, delayed DNA fragmentation), suggesting that the downstream amplification events and non-caspase cleavage events that are mediated by caspase- 3 cannot be carried out by caspases activated earlier in the pathway. In a similar but more dramatic way, if all caspase activity is blocked using broad spectrum caspase inhibitors, cells that progress beyond the mitochondrial commitment point typically exhibit features of necrosis rather than apoptosis. ${ }^{54,55}$

\section{Demolition: substrate attack and cellular collapse}

When the full complement of caspases that are necessary for the proper execution of the death programme have become activated, the final demolition phase can begin. We will not deal with the substrates themselves, as this topic is the subject of several recent reviews. The distinction between the amplification and demolition phase is obviously an artificial one, since it is presumed that substrates will become cleaved as soon as the caspase responsible for particular cleavage events are activated. However, it should be noted that whereas many of the caspases have a cytosolic localization, many of their known substrates are contained within the 
nucleus or other cellular compartments. Thus, there is likely to be some delay between activation of a caspase and the subsequent proteolytic attack of its preferred substrate(s). Movement of caspases between sub-cellular compartments in response to pro-apoptotic stimuli is an area of intensive investigation at present.

\section{'Initiator' and 'effector' caspases: a simple demarcation?}

Caspases have been grouped into either upstream/signalling/ initiator caspases and downstream/effector caspases, largely based upon their respective prodomain lengths. The rationale for this grouping derives primarily from the observation that long prodomain caspases (such as caspase-8) are typically recruited into membrane receptor complexes by means of adaptor proteins, and consequently, initiate the caspase cascade. Thus, the upstream caspases (those with long prodomains whose presumed function is to activate other caspases) would appear to be caspases $-2,-8,-9$ and -10 , and the effector caspases (those with short prodomains that are presumed to dismantle the cell) would appear to be caspases $-3,-6$ and -7 .

However, although this model is a very useful one, closer scrutiny of the available data indicates that this is an over-simplification. While caspases -8 and -9 have been shown to initiate caspase cascades in particular instances, there is scant evidence that caspase -2 and -10 function likewise. Although an adaptor molecule, RAIDD, has been identified that interacts with the prodomain of caspase-2 and is thought to link caspase-2 to TNFR1, ${ }^{25}$ it was subsequently shown that mice with targeted deletions in the CASP-2 gene have an intact TNF $\alpha$-induced death pathway. ${ }^{27}$ Furthermore, in studies employing in vitro systems to study the events in the cytochrome $c$ initiated caspase cascade, not only are the long-prodomain caspases -2, -8 and -10 activated in response to the Apaf-1-mediated activation of caspase- 9 , but their activation is dependent upon the actions of caspase-3, a short prodomain 'effector' caspase. ${ }^{30,56}$

These instances of the downstream activation of 'upstream' caspases have been further supported by the finding that the activation of caspases -2 and -8 is impaired in dexamethasone-induced apoptosis of thymocytes from $A P A F-1$ or CASP-9 null mice. ${ }^{57,58}$ it has also been demonstrated that following its activation by caspase- 9 , caspase- 3 feeds back on caspase- 9 thereby amplifying the cascade. ${ }^{30,47}$ Thus, it would seem that in a caspase cascade where caspase- 9 is apical, caspase- 3 does not function merely to cleave substrates but also acts to propagate and amplify the protease cascade by activating other caspases, including the long-prodomain caspases.

A further indication of the limitations of inferring the function of caspases upon the basis of their prodomains arose from studies undertaken using a positional scanning synthetic combinatorial library. ${ }^{59}$ This study placed the caspases into three groups based upon the preferred amino acid sequences adjacent to the site at which the caspases cleave. Group I caspases, whose preferred cleavage sequence was found to be (W/L)EHD, consisted of caspases $-1,-4$ and -5 , all of which are likely to be cytokine processing caspases. However, group II caspases, which display the sequence specificity of DEXD which is akin to the sequence at which many caspase substrates such as PARP are found to be cleaved, contain the short pro-domain caspases -3 and -7 but also the long pro-domain caspase, caspase-2 (although there is no evidence that they cleave the same set of substrates). Also, the group III caspases, whose favoured substrate sequence of $((\mathrm{I} / \mathrm{L} / \mathrm{V}) \mathrm{EXD})$ is similar to the sites at which caspases are cleaved upon their activation, include the short pro-domain effector caspase, caspase-6, in addition to the long pro-domain caspases, -8 and -9 .

Thus, it is probably incorrect to employ a simple demarcation of caspases into signalling or effector categories. The role that a particular caspase occupies within the activation cascade is likely to be partially contextdependent. Moreover, although the prodomains of caspases $-3,-6$ and -7 are only a few kilodaltons in size, it is not inconceivable that these caspases may interact with caspase clustering molecules through their prodomains, or other parts of the molecule. Conversely, it is also possible that some of the long-prodomain caspases, in addition to processing other caspases, may cleave cellular substrates during apoptosis. While studies from knockout mice have demonstrated the importance of caspases -8 and -9 in development, ${ }^{26,58,60}$ the defects exhibited by CASP-3 null mice may not be solely attributable to a lack of substrate cleavage. ${ }^{51}$ Although some apoptotic events such as the change in nuclear morphology are altered in mice lacking caspase-3, other events such as the exposure of phosphatidylserine and the cleavage of the caspase substrates fodrin, DFF45, lamin and gelsolin are delayed but not entirely abolished. ${ }^{61,62}$ Thus, it is possible that some of the defects in CASP-3 knockout mice arise as a result of improper dissemination of the caspase cascade and that this is a function of caspase- 3 that is as important as its role as an effector caspase.

\section{Future directions}

Although our understanding of caspase activation and effector function has improved dramatically over the past few years, there is much that remains to be explored. Little is known concerning the role of several members of the caspase family (caspases $-4,-5,-10,-12,-13,-14$ ) and whether they participate in apoptosis. It is likely that a number of these are involved in cytokine processing but this remains to be clarified. In this context, it is interesting to ask how cells are able to activate these caspases for the purpose of cytokine processing without triggering the death programme. Compartmentalization, rapid destruction of active caspases, and selective caspase inhibitors are likely to play important roles in this situation. It is also very likely that caspases have functions outside of the cell death or cytokine processing pathways. Interestingly, recent studies have implicated caspases in the denucleation that occurs during lens fibre differentiation and in cell attachment and migration. ${ }^{63,64}$ One thing is certain, figuring out the modus operandi of the serial killers of the cell is likely to keep us busy for some time to come. 


\section{Acknowledgements}

We gratefully acknowledge The Wellcome Trust for their ongoing support of research in our laboratory. SJ Martin is a Wellcome Trust Senior Fellow in Biomedical Research (047580). C Adrain is supported by a Department of Education Northern Ireland Studentship and was a Daniel O'Connell Fellow of NUI Maynooth. We also thank Enterprise Ireland (Grant SC1998-205) for support of some of the work discussed in this review.

\section{References}

1. Neurath $H$ (1984) Evolution of proteolytic enzymes. Science 224: $350-357$

2. Yuan J, Shaham S, Ledoux S, Ellis HM and Horvitz HR(1993) The C. eleganscell death gene ced-3 encodes a protein similar to mammalian interleukin $1-\beta$ converting enzyme. Cell 75: 641-652

3. Deveraux QL, Takahashi R, Salvesen GS and Reed JC (1997) X-linked IAP is a direct inhibitor of cell-death proteases. Nature 388: 300-304

4. Deveraux QL, Roy N, Stennicke HR, Van Arsdale T, Zhou Q, Srinivasula SM, Alnemri ES, Salvesen GS and Reed JC (1998) IAPs block apoptotic events induced by caspase- 8 and cytochrome $c$ by direct inhibition of distinct caspases. EMBO J. 17: 2215-2223

5. Irmler M, Thome M, Hahne M, Schneider P, Hofmann K, Steiner V, Bodmer JL, Schroter M, Burns K, Mattmann C, Rimoldi D, French LE and Tschopp J (1997) Inhibition of death receptor signals by cellular FLIP. Nature 388: 190-195

6. Thornberry NA and Lazebnik Y (1998) Caspases: enemies within. Science 281: $1312-1316$

7. Wang S, Miura M, Jung Y, Zhu H, Gagliardini V, Shi L, Greenberg AH and Yuan J (1996) Identification and characterization of Ich-3, a member of the interleukin1 beta converting enzyme (ICE)/Ced-3 family and an upstream regulator of ICE. J. Biol. Chem. 271: 20580-20587

8. Van de Craen M, Vandenabeele P, Declercq W, Van den Brande I, Van Loo G Molemans F, Schotte P, Van Criekinge W, Beyaert R and Fiers W (1997) Characterization of seven murine caspase family members. FEBS Lett. 403: $61-69$

9. Fraser AG and Evan GI (1997) Identification of a Drosophila melanogaster ICE/ CED-3-related protease, drICE. EMBO J. 16: 2805-2813

10. Song Z, McCall K and Steller H (1997) DCP-1, a Drosophila cell death protease essential for development. Science 275: 536-540

11. Inohara N, Koseki T, Hu Y, Chen S and Nunez G (1997) CLARP, a death effector domain-containing protein interacts with caspase 8 and regulates apoptosis. Proc. Natl. Acad. Sci. 94: 10717-10722

12. Chen P, Rodriguez A, Erskine R, Thach T and Abrams JM (1998) Dredd, a novel effector of the apoptosis activators reaper, grim, and hid in Drosophila. Dev. Biol. 201: $202-216$

13. Dorstyn L, Colussi PA, Quinn LM, Richardson H and Kumar S (1999) DRONC, an ecdysone-inducible Drosophila caspase. Proc. Natl. Acad. Sci. 96: 4307-4312

14. Shaham S (1998) Identification of multiple Caenorhabditis elegans caspases and their potential roles in proteolytic cascades. J. Biol. Chem. 273: 3510935117

15. Yaoita $Y$ and Nakajima K (1997) Induction of apoptosis and CPP32 expression by thyroid hormone in a myoblastic cell line derived from tadpole tail. J. Biol. Chem. 272: 5122-5127

16. AhmadM, Srinivasula SM, Wang L, Litwack G, Fernandes-Alnemri T and Alnemri ES (1997) Spodoptera frugiperda caspase-1, a novel insect death protease that cleaves the nuclear immunophilin FKBP46, is the target of the baculovirus antiapoptotic protein p35. J. Biol. Chem. 272: 1421-1424

17. Humke EW, Ni Jand Dixit VM (1998) ERICE, a novel FLICE-activatable caspase. J. Biol. Chem. 273: 15702-15707

18. Van de Craen M, Van Loo G, Pype S, Van Criekinge W, Van den Brande I, Molemans F, Fiers W, Declercq W and Vandenabeele P (1998) Identification of a new caspase homologue: caspase-14. Cell Death Differ. 5: 838-846

19. Wang S, Miura M, Jung YK, Zhu H, Li E and Yuan J (1998) Murine caspase-11, an ICE-interacting protease, is essential for the activation of ICE. Cell 92: 501-509

20. Gu Y, Wu J, Faucheu C, Lalanne JL, Diu A, Livingston DJ and Su MS (1995) Interleukin-1 beta converting enzyme requires oligomerization for activity of processed forms in vivo. EMBO J. 14: 1923-1931

21. Ashkenazi A and Dixit VM (1998) Death receptors: signaling and modulation Science 281: $1305-1308$
22. Pan G, Bauer JH, Haridas V, Wang S, Liu D, Yu G, Vincenz C, Aggarwal BB, Ni J and Dixit VM (1998) Identification and functional characterization of DR6, a novel death domain-containing TNF receptor. FEBS Lett. 431: 351-356

23. Yang X, Chang HY and Baltimore D (1998) Autoproteolytic activation of procaspases by oligomerization. Mol. Cell 1: 319-325

24. Muzio M, Stockwell BR, Stennicke HR, Salvesen GS and Dixit VM (1998) An induced proximity model for caspase-8 activation. J. Biol. Chem. 273: $2926-$ 2930

25. Duan H and Dixit VM (1997) RAIDD is a new 'death' adaptor molecule. Nature 385: $86-89$

26. Varfolomeev EE, Schuchmann M, Luria V, Chiannilkulchai N, Beckmann JS Mett IL, Rebrikov D, Brodianski VM, Kemper OC, Kollet O, Lapidot T, Soffer D, Sobe T, Avraham KB, Goncharov T, Holtmann H, Lonai P and Wallach D (1998) Targeted disruption of the mouse Caspase 8 gene ablates cell death induction by the TNF receptors, Fas/Apo1, and DR3 and is lethal prenatally. Immunity 9:267 276

27. Bergeron L, Perez GI, Macdonald G, Shi L, Sun Y, Jurisicova A, Varmuza S, Latham KE, Flaws JA, Salter JC, Hara H, Moskowitz MA, Li E, Greenberg A, Tilly $\mathrm{JL}$ and Yuan J (1998) Defects in regulation of apoptosis in caspase-2-deficient mice. Genes Dev. 12: $1304-1314$

28. Stennicke HR, Jurgensmeier JM, Shin H, Deveraux Q, WolfBB, Yang X, Zhou Q, Ellerby HM, Ellerby LM, Bredesen D, Green DR, Reed JC, Froelich CJ and Salvesen GS (1998) Pro-caspase-3 is a major physiologic target of caspase-8. J. Biol Chem. 273: 27084-27090

29. Hirata H, Takahashi A, Kobayashi S, Yonehara S, Sawai H, Okazaki T, Yamamoto K and Sasada M (1998) Caspases are activated in a branched protease cascade and control distinct downstream processes in Fas-induced apoptosis. J. Exp. Med. 187: 587-600

30. Slee EA, Harte MT, Kluck RM, Wolf BB, Casiano CA, Newmeyer DD, Wang HG, Reed JC, Nicholson DW, Alnemri ES, Green DR and Martin SJ (1999) Ordering the cytochrome $c$-initiated caspase cascade: hierarchical activation of caspases $-2,-3,-6,-7,-8$, and -10 in a caspase-9-dependent manner. J. Cell Biol. 144: $281-292$

31. Scaffidi C, Fulda S, Srinivasan A, Friesen C, Li F, Tomaselli KJ, Debatin KM, Krammer PH and Peter ME (1998) Two CD95 (APO-1/Fas) signaling pathways EMBO J. 17: 1675-1687

32. Luo X, Budihardjol, Zou H, Slaughter CandWang X (1998)Bid, a Bcl2 interacting protein, mediates cytochrome $c$ release from mitochondria in response to activation of cell surface death receptors. Cell 94: 481-490

33. $\mathrm{LiH}, \mathrm{ZhuH}, \mathrm{Xu}$ CJ and Yuan J (1998) Cleavage of BID by caspase 8 mediates the mitochondrial damage in the Fas pathway of apoptosis. Cell 94: 491-501

34. Gross A, Yin XM, Wang K, Wei MC, Jockel J, Milliman C, Erdjument-Bromage H, Tempst $P$ and Korsmeyer SJ (1999) Caspase cleaved BID targets mitochondria and is required for cytochrome $c$ release, while $B C L-X_{L}$ prevents this release but not tumor necrosis factor-R1/Fas death. J. Biol. Chem. 274: 1156-1163

35. Kluck RM, Bossy-Wetzel E, Green DR and Newmeyer DD (1997) The release of cytochrome c from mitochondria: a primary site for $\mathrm{Bcl}-2$ regulation of apoptosis. Science 275: $1132-1136$

36. Yang J, Liu X, BhallaK, Kim CN, Ibrado AM, Cai J, Peng TI, Jones DP and Wang X (1997) Prevention of apoptosis by Bcl-2: release of cytochrome $\mathrm{C}$ from mitochondria blocked. Science 275: 1129-1132

37. Darmon AJ, Nicholson DW and Bleackley RC (1995) Activation of the apoptotic protease CPP32 by cytotoxic T-cell-derived granzyme B. Nature 377: 446-448

38. Martin SJ, Amarante-Mendes GP, Shi L, Chuang T-H, Casiano CA, O'Brien GA, Fitzgerald P, Tan EM, Bokoch GM, Greenberg AH and Green DR (1996) The cytotoxic cell protease granzyme $B$ initiates apoptosis in a cell-free system by proteolytic processing and activation of the ICE/Ced-3 family protease, CPP32, via a novel two-step mechanism. EMBO J. 15: 2407-2416

39. Yang X, Stennicke HR, Wang B, Green DR, Janicke RU, Srinivasan A, Seth P, Salvesen GS and Froelich C (1998) Granzyme B mimics apical caspases. Description of a unified pathway for trans-activation of executioner caspase-3 and -7. J. Biol. Chem. 273: 34278-34283

40. Liu X, Kim CN, Yang J, Jemmerson R and Wang X (1996) Induction of apoptotic program in cell-free extracts: requirement for dATP and cytochrome c. Cell 86: $147-157$

41. Susin SA, Lorenzo HK, Zamzami N, Marzo I, Snow BE, Brothers GM, Mangion J, Jacotot E, Costantini P, Loeffler M, Larochette N, Goodlett DR, Aebersold R, Siderovski DP, Penninger JM and Kroemer G (1999) Molecular characterization of mitochondrial apoptosis-inducing factor. Nature 397: 441-446 
42. Green DR and Reed JC (1998) Mitochondria and apoptosis. Science 281: $1309-1312$

43. Bossy-WetzelE, NewmeyerDD and Green DR (1998) Mitochondrial cytochrome c release in apoptosis occurs upstream of DEVD-specific caspase activation and independently of mitochondrial transmembrane depolarization. EMBO J. 17: $37-49$

44. Vander Heiden MG, Chandel NS, Williamson EK, Schumacker PT and Thompson CB (1997) Bcl-xL regulates the membrane potential and volume homeostasis of mitochondria. Cell 91: 627-637

45. Zou H, Henzel WJ, Liu X, Lutschg A and Wang X (1997) Apaf-1, a human protein homologous to $\mathrm{C}$. elegans CED-4, participates in cytochrome c-dependent activation of caspase-3. Cell 90: 405-413

46. Li P, Nijhawan D, Budihardjo I, Srinivasula SM, Ahmad M, Alnemri ES and Wang X (1997) Cytochrome $c$ and dATP-dependent formation of Apaf-1/caspase- 9 complex initiates an apoptotic protease cascade. Cell 91: 479-489

47. Srinivasula SM, Ahmad M, Fernandes-Alnemri T and Alnemri ES (1998) Autoactivation of procaspase-9 by Apaf-1-mediated oligomerization. Mol. Cell 1: 949-957

48. Zou H, Li Y, Liu X and Wang X (1999) An APAF-1 Cytochrome c multimeric complex is a functional apoptosome that activates procaspase-9. J. Biol. Chem 274: $11549-11556$

49. Adrain C, Slee EA, Harte MT and Martin SJ (1999) Regulation of Apaf-1 oligomerization and apoptosis by the WD-40 repeat region. J. Biol. Chem. 274 20855-20860

50. Pan G, Humke EW and Dixit VM (1998) Activation of caspases triggered by cytochrome $c$ in vitro. FEBS Lett. 426: 151-154

51. Kuida K, Zheng TS, Na S, Kuan C-Y, Yang D, Karasuyama H, Rakic P and Flavel RA (1996) Decreased apoptosis in the brain and premature lethality in CPP32 deficient mice. Nature 384: 368-372

52. Jänicke RU, SprengartML, WatiMR and Porter AG (1998) Caspase-3 is required for DNA fragmentation and morphological changes associated with apoptosis. J. Biol. Chem. 273: 9357-9360

53. Jänicke RU, NgP, Sprengart ML and Porter AG (1998) Caspase-3 is required for alpha-fodrin cleavage but dispensable for cleavage of other death substrates in apoptosis. J. Biol. Chem. 273: 15540-15545
54. McCarthy NJ, Whyte MK, Gilbert CS and Evan GI (1997) Inhibition of Ced-3/ICErelated proteases does not prevent cell death induced by oncogenes, DNA damage, or the Bcl-2 homologue Bak. J. Cell Biol. 136: 215-227

55. Amarante-Mendes GP, Finucane DM, Martin SJ, Cotter TG, Salvesen GS and Green DR (1998) Anti-apoptotic oncogenes prevent caspase-dependent and independent commitment for cell death. Cell Death Differ. 5: 298-306

56. Swanton E, Savory P, Cosulich S, Clarke P and Woodman P (1999) Bcl-2 regulates a caspase-3/caspase-2 apoptotic cascade in cytosolic extracts. Oncogene 18: 1781-1787

57. Yoshida H, Kong YY, Yoshida R, Elia AJ, Hakem A, Hakem R, Penninger JM and Mak TW (1998) Apaf1 is required for mitochondrial pathways of apoptosis and brain development. Cell 94: 739-750

58. Hakem R, Hakem A, Duncan GS, Henderson JT, Woo M, Soengas MS, Elia A, de la Pompa JL, Kagi D, Khoo W, Potter J, Yoshida R, Kaufman SA, Lowe SW, Penninger JM and Mak TW (1998) Differential requirement for caspase 9 in apoptotic pathways in vivo. Cell 94: 339-352

59. Thornberry NA, Rano TA, Peterson EP, Rasper DM, Timkey T, Garcia-Calvo M, Houtzager VM, Nordstrom PA, Roy S, Vaillancourt JP, Chapman KT and Nicholson DW (1997) A combinatorial approach defines specificities of members of the caspase family and granzyme B. Functional relationships established for key mediators of apoptosis. J. Biol. Chem. 272: 17907-17911

60. Kuida K, Haydar TF, Kuan CY, GuY, Taya C, Karasuyama H, Su MS, Rakic P and Flavell RA (1998) Reduced apoptosis and cytochrome c-mediated caspase activation in mice lacking caspase 9. Cell 94: 325-337

61. Zheng TS, Schlosser SF, Dao T, Hingorani R, Crispe IN, Boyer JL and Flavell RA (1998) Caspase-3 controls both cytoplasmic and nuclear events associated with Fas-mediated apoptosis in vivo. Proc. Natl. Acad. Sci. USA 95: 13618-13623

62. Woo M, Hakem R, Soengas MS, Duncan GS, Shahinian A, Kagi D, Hakem A, McCurrach M, Khoo W, Kaufman SA, Senaldi G, Howard T, Lowe SW and Mak TW (1998) Essential contribution of caspase 3/CPP32 to apoptosis and its associated nuclear changes. Genes Dev. 12: 806-819

63. Ishizaki Y, Jacobson MD and Raff MC (1998) A role for caspases in lens fibre differentiation. J. Cell Biol. 140: 153-158

64. Watanabe $Y$ and Akaike T (1999) Possible involvement of caspase-like family in maintanance of cytoskeleton integrity. J. Cell Physiol. 179: 45-51 